Tarih Kültür ve Sanat Araştırmaları Dergisi

Revue des Recherches en Histoire Culture et Art

مجلة البحوث التاريخية والثقافية والفنية
Vol. 6, No. 5, November 2017

Copyright (C) Karabuk University

http://kutaksam.karabuk.edu.tr

\title{
DOI: 10.7596/taksad.v6i5.1258
}

Citation: Andrianova, N., Nizamieva, L., Nazarova, G., Ostroumova, O., \& Leblanc, C. (2017). The Development of Students' Cognitive Self-Study While Teaching Reading in FL Training. Journal of History Culture and Art Research, 6(5), 321-326. doi:http://dx.doi.org/10.7596/taksad.v6i5.1258

\section{The Development of Students' Cognitive Self-Study While Teaching Reading in FL Training}

\author{
Natalia S. Andrianova ${ }^{1}$, Liliya R. Nizamieva ${ }^{2}$, \\ Gulnara I. Nazarova ${ }^{3}$, Olga F. Ostroumova ${ }^{4}$, Cécile Leblanc ${ }^{5}$
}

\begin{abstract}
In the informational society while teaching foreign languages the development of students' skills aimed at searching, analyzing, critical thinking, processing and using the obtained information in the productive speech activity is in demand. In this context, the problem of students' cognitive self-study development, aimed at "revealing" knowledge while reading, is becoming increasingly important as reading while teaching foreign languages not only contributes to self-development and self-reflection, but also to the formation of a cross-cultural and linguistic personality, which is a priority of linguistic education. The solution of the above-mentioned problems has defined the aim of our research: it is the development and implementation of technologies for optimizing students' self-study in teaching reading. In the course of our experimental work the implementation of the principle of multi-level approach in the form of five interrelated elements in teaching reading - from the level of mastering reading techniques to the level of critical reading and stylistic comprehension reading - contributed to the ultimate development and improvement of students' constructive-creative self-study. During the experimental work while testing the effectiveness of our methods of cognitive-practical activities, we concluded that in the process of teaching foreign languages, these methods are an effective way of teaching reading, activating students' self-study, forming linguistic creativity, which manifests itself in the ability to produce oral and written discourses based on the creative potential development of a linguistic personality. The results obtained in the experiment can be used in educational process while creating and implementing the algorithm of organizing students' self-study while teaching foreign languages.
\end{abstract}

Keywords: Cognitive self-study, Methods of cognitive-practical activities, Teaching and methodological materials, Teaching reading, Cognitive-communicative methods, A linguistic personality.

\footnotetext{
${ }^{1}$ Kazan Federal University, Leo Tolstoy Institute of Philology and Intercultural Communication. E-mail: natalia_an83@mail.ru

${ }^{2}$ Kazan Federal University, Leo Tolstoy Institute of Philology and Intercultural Communication

${ }^{3}$ Kazan Federal University, Leo Tolstoy Institute of Philology and Intercultural Communication

${ }^{4}$ Kazan Federal University, Leo Tolstoy Institute of Philology and Intercultural Communication

${ }^{5}$ Paris III-Sorbonne-Nouvelle, Applied foreign languages department
} 


\section{Introduction}

The problem of students' cognitive self-study development is due to the ever-growing need to optimize and intensify the educational process, as well as to the formation of a creative and self-developing personality (Antonova et al., 2016). The complex study of the problem, as well as the specific one relating to different subjects in secondary and higher education were the object of many Russian and foreign researchers' works (Zimnyaya, 2004; Kraevsky \& Khutorskoi, 2007; Carneiro et al., 2011; Dejean et al., 2011). Nevertheless, the possibilities of self-study formation in the process of mastering the speech activity while learning a foreign language, in our opinion, are not thoroughly investigated. To a certain extend this is due to the fact that the formation of speech skills, but not knowledge itself, plays the leading role in the process of mastering speech activity. It doesn't entirely correspond to the very term "cognitive self-study" that primarily means self-acquisition of knowledge. Mastering the skills, that is predominant in the subjects with leading component "ways of activity", significantly differs from the acquisition of new knowledge, both in its content and process. Therefore, we propose a new notion "cognitive-speech self-study", which is defined as the self-study ability to master speech skills according to the target language rules (Nizamieva et al., 2016). Its practical indicator is the level of development of certain speech acts.

\section{Methods}

There can be three levels of speech self-study development in teaching a foreign language: copying, reproductive-creative and constructive-creative. The copying level of cognitive-speech self-study is the ability to analyze, understand and learn a typical speech pattern and master its simplest transfer to cope with similar speech tasks. The reproductive-creative level is characterized by the ability to transfer and expand a speech pattern, to choose one of the mastered patterns and practically use it to solve a similar problem, i.e. to implement a complicated transfer into similar speech conditions. The constructivecreative level of cognitive-creative self-study implies the ability to creatively use formed speech skills and on the basis of their improvement to implement a complicated transfer to complete new speech tasks.

As the leading method of cognitive-speech self-study we put forward the methods of cognitive-practical activity, as a universal tool for teaching and learning. Being an effective way of learning, these methods allow students to master the mechanism of acquiring new knowledge and skills, thereby forming their cognitive-speech self-study.

The system of cognitive-practical activity methods was the theoretical base of the set of books in French teaching in the secondary school. Writing textbooks and manuals of a new type was due to the need of using the cognitive-communicative method while teaching foreign languages, that is guided by a productive speech activity, in contrast to the traditional reproductive one.

In this article we will only study the skills' formation for comprehending a foreign text, so the main attention will be paid to the textbooks and reading books, which contain authentic texts of linguisticcultural nature that allow the students to master the modern French language and plunge into a different national culture, thus contributing to the cognition of native speakers' mentality, their customs, traditions, lifestyle and stereotypes (Subich et al., 2016).

The fundamental principle of a multilevel approach to teaching reading suggests that each level of penetrating into a foreign text corresponds to a particular cognitive-practical activity method. The logic of using this principle leads to the following levels of penetrating into a text:

- $\quad$ Tthe level of mastering reading techniques;

- Tthe level of general comprehension reading; 
- $\quad$ The level of detailed reading;

- $\quad$ The level of critical reading;

- $\quad$ The level of stylistic comprehension reading.

The above-mentioned five levels in the process of teaching reading in the suggested system correspond to specific cognitive-practical activity methods, and each subsequent method is based on the previous one and involves the development of a certain level of students' self-study.

\section{Results}

The main forming experiment was organized in five series, corresponding to the stages of learning to read. Each series of the experiment had its own purpose, the working hypothesis and the methodology for teaching in the experimental groups according to theoretically proved principles and conditions for functioning of the cognitive-practical activity methods in teaching reading. The experiment in the control groups was carried out according to the traditional method during the same period as in the experimental groups. Tests were carried out without visual aids and without the teacher's help. The quality of the speech activity was determined by the parameters specified for each series of the experiment. In each series there were three tests at the initial, intermediate and final stages of teaching.

The results of experimental teaching confirmed the effectiveness of the developed system of methods of cognitive-practical activities in teaching reading, as according to all suggested criteria the quantitative indicators of experimental teaching were higher than in the groups taught by the traditional method. The objective indicator of cognitive-speech self-study development has been the development of speech quality, which is inseparably connected with the improvement of students' cognitive abilities and expanding their self-study. The results of experimental teaching reading in the experimental and control groups are shown in Figure 1.

Figure 1. Results of experimental teaching

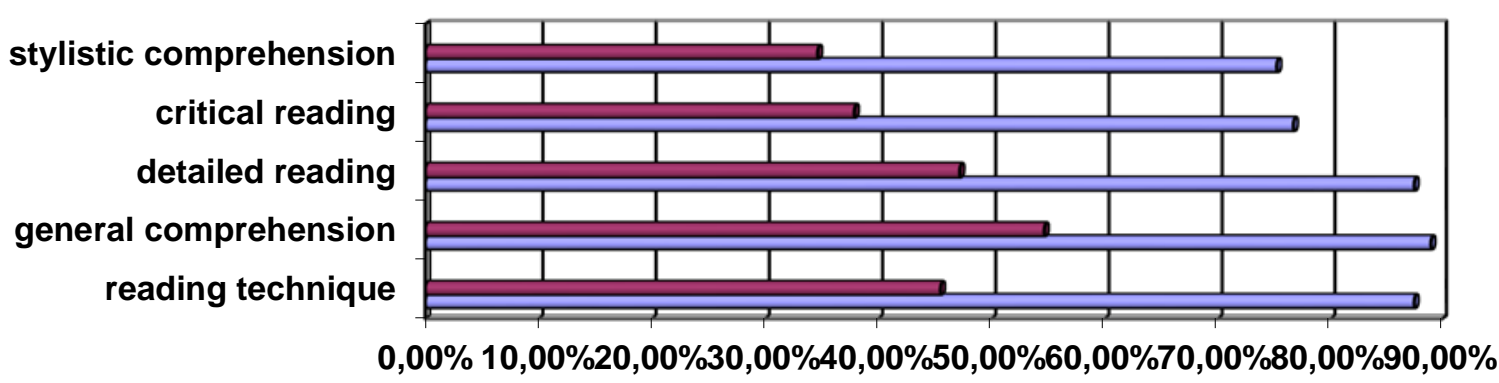

口

口control groups

\section{Discussion}

The method of mastering reading techniques works on the copying level of self-study and involves the acquirement of phonographic correspondences. At the stage of creating basic recommendations of activities comprehension and interpretation of graphics of the alphabetic letters, the articulation features of language sounds, the rules of reading, stress in words and reading words in speech take place. At the 
stage of the skills' formation strong phonographic correspondences are set, the pronunciation of letter combinations are acquired as well as awareness of the semantic meaning of graphic symbols, the formation of receptive-active and receptive-passive grammatical reading skills take place. At the initial and practical stages of teaching reading techniques the use of visual aids, avoiding linguistic difficulties, the use of appropriate exercises for drilling and mastering reading skills, the organization of practice for mastering a foreign language graphic symbols are necessary.

The method of general comprehension reading is based on the formed basic technical reading skills and suggests a gradual transfer from the copying to the reproductive-creative level of self-study using visual aids at the stage of further skills' development. The content of the method includes clear instructions for a student, which should contain the target setting that reflects the desired speech act, the desired speech product and the planned outcome, a concise summary of the program of actions, recommendations forecasting content of the text before reading and recommendations for controlling its understanding. At the initial stage a student masters the basic skills of finding and processing information at the level of meaning, and the ability to predict the content of the text according to the linguistic data and structural components of the text. The adapted and authentic materials are used in teaching process with obligatory avoiding linguistic difficulties before reading the text. Further development of speech skills involves students' transfer to reproductive-creative level of self-study on the basis of the increased level of knowledge and the transfer of formed skills into a similar speech situation with a minimized drilling stage on the part of a teacher.

The method of detailed reading is based on formed skills of general comprehension reading and also works at the level of reproductive-creative self-study. This level involves the extensive use of visual aids on the stage of speech skills' development. The content of the method should include a thesaurus of lexical and grammatical phenomena of a language and structural components of texts of different styles and genres, including various types of text documents (literary excerpts, newspaper articles, popularscience texts, different types of correspondence). When mastering the skills of a detailed reading the mechanisms of anticipation and transfer by analogy play an important role. The conditions for the functioning of the method are as follows: following a number of requirements for the selection of texts, the use of visual aids, pre-reading tasks that prepare students for the perception of the text, a variety of textual materials, post-reading tasks aimed at controlling the detailed comprehension of the content. The developing effect of using this method is in the students' ability to understand any text at the level of the thesaurus of lexical and grammatical phenomena of a language and structural-semantic components of texts of different styles and genres.

The method of the critical reading is based on the formed at the previous stage skills of detailed reading and helps to realize further qualitative transfer from the level of reproductive-creative self-study into constructive-creative level with gradual doing without visual aids as far as students' speech skills improve. The students are offered the tasks to look through the text and to sum up the events and actions of the characters, their characteristics, to analyze, synthesize, comment and give their own predictions and proposals. The content of this method includes not only thesaurus of lexical and grammatical phenomena of a language and structural components of a text, but the function of the text and communicative intention of the author as well. Reading of a text at the level of reproductive-creative self-study involves the analysis of the presented speech pattern, the solution of the similar speech problem with the elements of creativity and partially using the pattern. Students' self-study of new speech tasks with the partial assistance of the teacher or complete absence of it indicates that the students transfer to the level of constructive-creative self-study. We are talking about the automation of skills for critical information assessment and giving their own opinion on the basis of their transfer to new speech situations, while 
creatively processing the information apart of the text. This method allows us to develop creative abilities of students (Sadykova \& Shelestova, 2016) and to use their background knowledge.

The method of stylistic comprehension reading is based on previously formed skills of detailed and critical reading. In the process of teaching there is a transfer from the reproductive-creative to constructivecreative self-study, when the speech activity of students on understanding and interpreting the text takes place without visual aids. The content of the method is a thesaurus of lexical, grammatical and stylistic language phenomena, the structural components of a text, literary texts, varieties of literary styles, their compositional speech forms and genres, types of speech, function and communicative intention of the author. At the level of reproductive-creative self-study there is a work on the analysis of the speech pattern as the scheme of actions while transferring into a new speech situation, the solution of the similar speech problem with elements of creativity and partially using the pattern. The constructive-creative level of self-study provides the automation of skills of stylistic interpretation of a text and giving their own opinions, their transfer to new speech situations with a minimized drilling stage or its complete absence. The ultimate goal is a self-analysis of a literary text at all levels.

During the experiment, the aim of which was to check the effectiveness of our methods, we followed the stages of formation and development of language skills in the process of teaching reading, starting with the technical skills of reading and finishing with the stylistic comprehension reading, as well as their respective stages of students' cognitive speech self-study development. The experimental teaching was conducted on the basis of the secondary schools teaching French as a foreign language in the terms of bilingualism, that distinguishes the language situation in the Republic of Tatarstan, with two state languages - Russian and Tatar. Some researchers have noted that "bilingual students show high results in reading skills and comprehension tasks, which can be partly explained by extended use of contextual comprehension in everyday situations when students have to deal with communication problems caused by incomplete domination of one of the languages" (Klimchak \& Fatkhutdinova, 2015). However, these students often face the problem of interference caused by systemic differences between languages. "In case of bilingual students, the situation is complicated by the presence of two languages that can bear systemic differences, belong to different language families and usually cause interferences in the process of learning a foreign language" (Pleuchova \& Klimchak, 2014). The bilingualism of the classroom was taken into account in our experimental work. In order to optimize the learning process, we relied on the positive influence of native languages and tried to minimize unwanted interference that was achieved by the appropriate organization of educational material.

\section{Conclusion}

In the course of research, we identified the interconnection and interdependence between the development of students' cognitive self-study and their reading skills. It was theoretically and experimentally proved that the use of cognitive-practical activity methods in teaching reading helps to expand the possibilities of the educational process, promotes the development of students' cognitivespeech self-study and improves the level of comprehending a written text.

Practically our developed methods are self-developing system of mastering reading, i.e., as a result of the above methods' use a student demonstrates the ability to understand any text for general, detailed, critical and stylistic comprehension. The experiment of using the authors' set of books in teaching French in the secondary schools of the Republic of Tatarstan shows the high efficiency of the developed methodology in the formation of foreign-language skills and in the development of students' cognitivespeech self-study. 


\section{Acknowledgements}

The work is performed according to the Russian Government Program of Competitive Growth of Kazan Federal University.

\section{References}

Antonova, N. V.; Vassilieva, V. N. \& Kononenko, M. V. (2016). The problem of quality of education in foreign language teaching. Journal of Language and Literature, 7(2), 159-162.

Carneiro, R.; Lefrere, P.; Steffens, K. \& Underwood, J. (2011). Self-Regulated Learning in Technology Enhanced Learning Environments. Rotterdam: Sense Publishers.

Dejean, C. ; Mangenot, F. \& Soubrié, T. (2011). Apprentissages formels et informels, autonomie et guidage. Actes du colloque EPAL 2011, Université Stendhal. Grenoble 3, 24-26 juin 2011, pp. 9-15.

Klimchak, O. \& Fatkhutdinova, V. (2015). Teaching languages in a multicultural society. 8th International Conference of Education, Research and Innovation. 18-20 November, 2015, Seville, Spain, pp. 3801-3804.

Kraevsky, V. V. \& Khutorskoi, V. V. (2007). Teaching bases. Didactics and methodology. Moscow: Academy.

Nizamieva, L. R.; Nazarova, G. I. \& Ostroumova, O. F. (2016). Teaching French as a Foreign Language in the Multilingual Environment (The Example of Tatarstan Republic). The Social Sciences, 11(6), 1035-1041.

Pleuchova, E. A. \& Klimchak, O. V. (2014). Modern tendencies in teaching foreign languages: from a traditional task to a digital task. 6th International Conference on Education and New Learning Technologies. Barcelona, Spain, 7-9 July, 2014, pp. 126-129.

Sadykova, A. G. \& Shelestova, O. V. (2016). Creativity development: The role of foreign language learning. International Journal of Environmental and Science Education, 11(15), 8163-8181.

Subich, V. G.; Shangaraeva, L. F. \& Zakirova, L. R. (2016). Improvement of the English language communicative competencies by means of authentic texts. Journal of Language and Literature, 7(2), 257261.

Zimnyaya, I. A. (2004). Key competences as an effectively-target base of the competence approach to education. Moscow: Research centre on specialists' training quality issues. 